HORIZON-INDUCED OPTIMISM AS A GATEWAY TO EARNINGS

MANAGEMENT

\author{
A Dissertation \\ Presented to the Faculty of the Graduate School \\ of Cornell University \\ In Partial Fulfillment of the Requirements for the Degree of \\ Doctor of Philosophy
}

by

Hamilton Scott Asay

August 2013 
(C) 2013 Hamilton Scott Asay 


\title{
HORIZON-INDUCED OPTIMISM AS A GATEWAY TO EARNINGS MANAGEMENT
}

\author{
Hamilton Scott Asay, Ph. D. \\ Cornell University 2013
}

Recent work in accounting suggests managerial optimism can lead managers to escalate income-increasing earnings management. In this paper, I examine how a fundamental attribute of the earnings management setting - the amount of time between the earnings management decision and the future reversal - serves as one potential source of managerial optimism. I conduct two experiments to test whether the amount of time between the earnings management decision and the future reversal systematically induces optimism and increases participants' propensity to engage in behavior that is analogous to accruals-based and real earnings management, holding constant incentives, innate optimism, agency frictions, and the information environment. My results indicate that the time between the earnings management decision and the future reversal could increase both forms of earnings management by leading managers to overestimate their ability to compensate for current-period earnings management through strong future performance. 
BIOGRAPHICAL SKETCH

Scott Asay received a B.S. in Accounting from Brigham Young University in 2007 and a MAcc from Brigham Young University in 2008. He received an M.S. in Management from Cornell University in 2012 and a Ph.D. in Management from Cornell University in 2013. His research focuses on factors that affect the production, disclosure, and use of information in the financial reporting environment. Scott joined the faculty at the University of Iowa in June, 2013.

In his free time, Scott enjoys being with his wife, Trina, and his three daughters, Evelyn, Allison, and Natalie. He especially enjoys hiking, playing games, and reading with his family. 


\section{TO MY PARENTS, BLAINE AND PATRICE \\ for their counsel and encouragement}

\section{TO MY WIFE, TRINA}

for her unwavering support, faith, endurance, and love

TO MY DAUGHTERS, EVELYN, ALLISON, AND NATALIE

for their love and laughter 


\section{ACKNOWLEDGMENTS}

I am indebted to my advisor, Bob Libby for his mentoring and guidance throughout my doctoral program. I am also very grateful for the valuable advice and feedback provided by my dissertation committee members: Bob Libby (Co-Chair), Mark Nelson (Co-Chair), Jay Russo, and Giles Hooker. This dissertation also benefited from helpful comments from Jeremy Bentley, Rob Bloomfield, Willie Choi, Brooke Elliott, Scott Emett, Harry Evans, Jeff Hales, Vicky Hoffman, Karim Jamal, Eldar Maksymov, Don Moser, Ken Merkley, Joe Pacelli, Mark Peecher, Joowon Park, Kristi Rennekamp, Manoj Thomas, Aaron Zimbelman, and workshop participants at the University of Alberta, Cornell University, Georgia Institute of Technology, the University of Illinois, the University of Iowa, and the University of Pittsburgh. I gratefully acknowledge financial support from the Samuel Curtis Johnson Graduate School of Management at Cornell University and the Deloitte Foundation. I am also grateful to Doug Prawitt and other faculty involved with the Ph.D. Prep Program at Brigham Young University, for preparing me to enter a doctoral program. Finally, this work would not have been possible without the patience, love, and support of my parents, my wife, Trina, and my daughters. 


\section{TABLE OF CONTENTS}

Biographical Sketch....................................................................................... iv

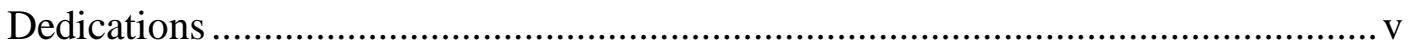

Acknowledgements ……………………............................................................ vi

Table of Contents ………................................................................................ vii

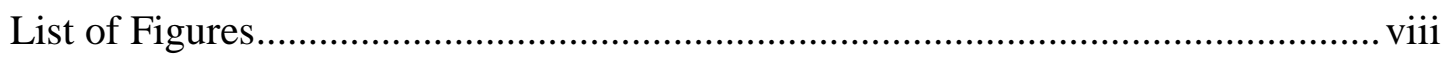

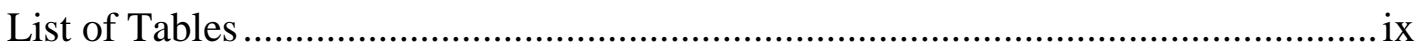

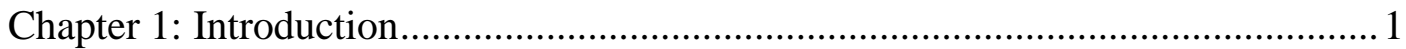

Chapter 2: Background and Development of Hypotheses ........................................

2.1 The Optimism Bias..............................................................................

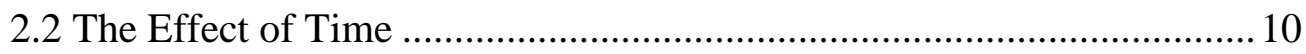

2.3 Earnings Management ............................................................................. 11

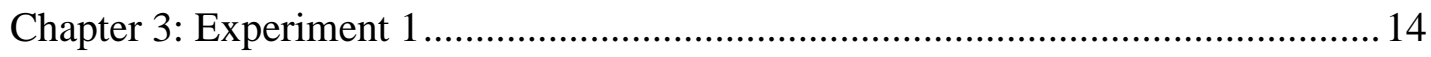

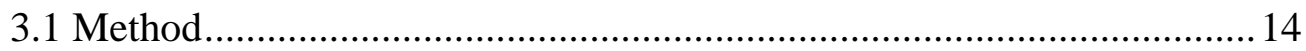

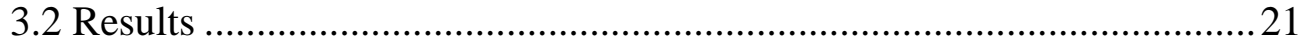

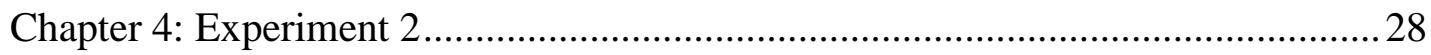

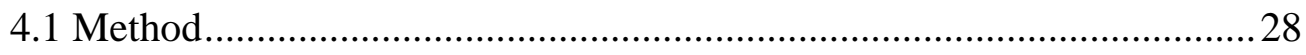

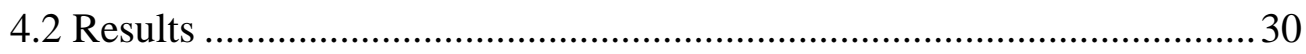

Chapter 5: Additional Discussion and Analysis ........................................................... 37

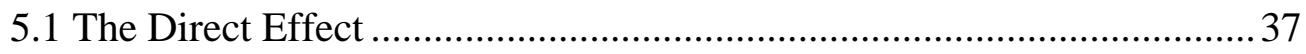

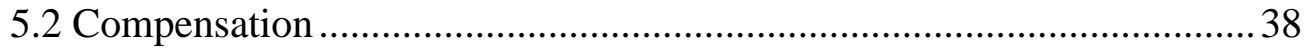

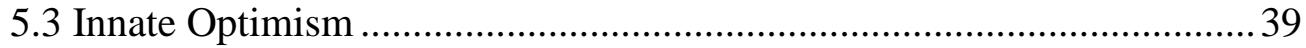

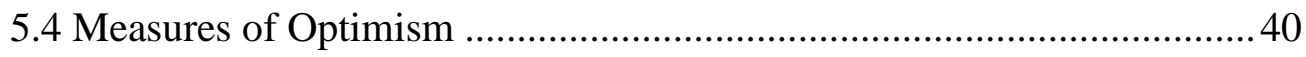

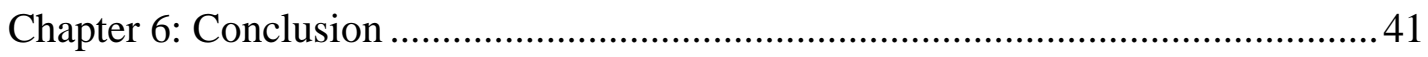

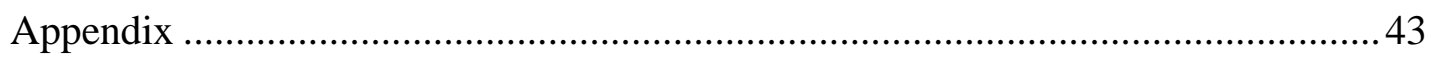

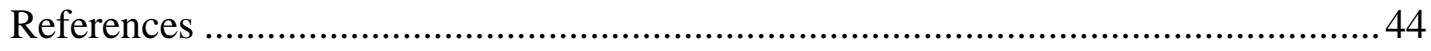




\section{LIST OF FIGURES}

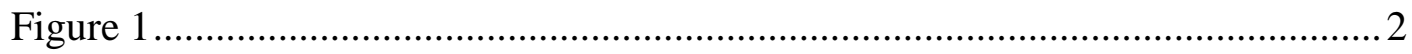

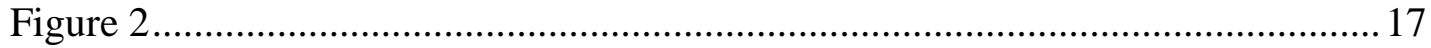




\section{LIST OF TABLES}

Table 1. Experiment 1: Descriptive Statistics and Univariate Analyses ....................22

Table 2. Experiment 1: Tests of Horizon-Induced Optimism and Implications for

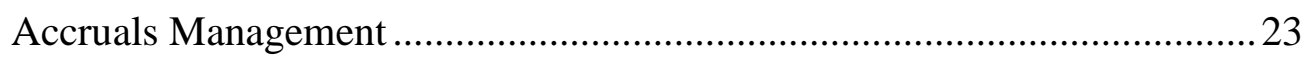

Table 3. Experiment 2: Descriptive Statistics and Univariate Analyses .....................32

Table 4. Experiment 2: Tests of Horizon-Induced Optimism and Implicates for Real

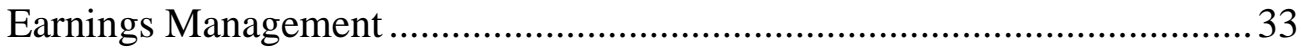




\section{CHAPTER 1}

\section{INTRODUCTION}

Earnings management that increases earnings in the current period often does so at the expense of future earnings (hereafter, "the reversal"). ${ }^{1}$ Since managers' welfare is affected by their ability to meet both current and future earnings targets, their beliefs about future performance become an important factor in the currentperiod earnings management decision. Recent research supports this idea, suggesting that optimism about future performance can lead managers to manage earnings because they overestimate their ability to compensate for current-period earnings management through strong future performance (Schrand and Zechman 2012).

Much of the prior research on the effects of optimistic beliefs on earnings management and other management decisions has treated optimism as a personal trait (e.g., Hales, Wang, and Williamson 2012; Hribar and Yang 2011; Malmendier and Tate 2005; Schrand and Zechman 2012), but environmental factors also can affect managerial optimism (e.g., Libby and Rennekamp 2011; Hales and Kachelmeier 2008). In this paper, I suggest that an important attribute of the earnings management setting contributes to optimism-induced earnings management. Specifically, I examine (1) whether the amount of time between the current period and the period when the reversal occurs systematically increases managers' optimism about future performance compared to current performance (hereafter "horizon-induced optimism") and (2)

\footnotetext{
${ }^{1}$ I use the term "reversal" to refer to the effect of both accruals management and real earnings management on future earnings. While real earnings management does not reverse mechanically like accruals management, the sign of the effect on future earnings will typically be opposite of the sign of the effect on current earnings.
} 
whether horizon-induced optimism increases the likelihood that managers engage in income-increasing earnings management. This causal chain is depicted in Figure 1. I conduct two experiments that hold constant participants' incentives, participants' innate optimism, and the information environment, and address these questions in two settings that are analogous to accruals-based and real earnings management.

\section{Figure 1. Hypothesized causal relations.}

\begin{tabular}{|c|c|c|c|}
\hline $\begin{array}{c}\text { Time between } \\
\text { Current Period } \\
\text { and Period when } \\
\text { Reversal Occurs }\end{array}$ & H1 (+) & $\begin{array}{c}\text { Optimistic Beliefs } \\
\text { and Forecasts } \\
\text { about Future } \\
\text { Performance }\end{array}$ & H2 (+) \\
\cline { 3 - 4 }
\end{tabular}

Understanding how the time between the current period and the reversal period might lead managers to overestimate their ability to compensate for current-period earnings management through strong future performance is important because earnings management is costly and the potential benefits are often short-lived (e.g., Bhojraj, Hribar, Picconi, and McInnis 2009; Myers, Myers, and Skinner 2007; Teoh, Wong and Rao 1998). In addition, unlike managerial optimism that results from managers' innate characteristics, optimism that varies systematically with environmental factors is unlikely to be successfully mitigated by screening managers based on their innate optimism. Understanding how fundamental attributes of accounting settings affect optimism is an important first step to identifying effective interventions to reduce these effects (e.g., Kadous, Krische, and Sedor 2006).

The ability of horizon-induced optimism to produce the effects outlined in Figure 1 is open to question for two reasons. First, prior tests of horizon-induced 
optimism in the psychology literature typically involve manipulating the temporal distance to a future event in a single-period environment, but earnings management decisions are made after receiving feedback about pre-managed performance in the current period. Prior research suggests that this feedback might reduce horizoninduced optimism (Shepperd, Oullette, and Fernandez 1996). Second, most prior studies on horizon-induced optimism focus on individuals' stated beliefs rather than on the actions they take as a result of those beliefs. Prior work provides evidence of a disconnect between beliefs and actions (see, e.g., Seybert and Bloomfield 2009). It is quite possible that the process of making formal forecasts and taking actions to shift reported performance between periods might be sufficient for participants to reconsider their biased judgments.

I examine the effect of the time between the current period and the reversal period in settings similar to accruals management and real earnings management. I test whether horizon-induced optimism affects both types of earnings management because there are key differences between accruals management and real earnings management that might affect the generalizability of the effect. For example, many types of accruals management (e.g., overestimating percentage-of-completion, underestimating bad debts, etc.) involve borrowing earnings from a future period to increase earnings in the current period, which decreases earnings by the same amount when the accruals reverse. In contrast, many types of real earnings management (e.g., delaying the start of a project, cutting advertising or R\&D, etc.) increase earnings in the current period but create a more challenging future environment that makes it more difficult to meet performance targets in future periods. Here, the amount and timing of 
the future reversal is known with less precision for real earnings management than it is with accruals management. This uncertainty could affect whether or how horizoninduced optimism influences earnings management behavior.

To operationalize the accruals management setting, participants in Experiment 1 are paid to perform an abstract task during two periods. Following their participation in Period 1, participants receive their score, forecast their score for Period 2, and choose between two options designed to capture the features of accruals management. Participants who choose the "accruals management" option borrow correct responses from Period 2 to enhance their Period 1 score and qualify for a Period 1 bonus. Because their Period 2 score is reduced by the borrowed amount, this choice increases the level of performance required to meet a performance target in Period 2 and makes it more difficult to earn a Period 2 bonus. Participants who choose the "no accruals management" option do not borrow correct responses from Period 2 and therefore receive whatever bonuses their Period 1 and Period 2 performance qualifies them to receive.

Experiment 2 modifies the earnings management decision to capture important features of real earnings management. Participants who choose the "real earnings management" option qualify for a Period 1 bonus by accepting a more challenging task environment in Period 2 that makes it more difficult to earn a Period 2 bonus. Participants who choose the "no real earnings management" option do not face a more challenging task environment in Period 2 and therefore receive whatever bonuses their Period 1 and Period 2 performance qualifies them to receive. 
In both experiments, I manipulate between participants the amount of time between the current period (when the earnings management decision is made) and the reversal period by varying whether Period 2 occurs the following month or immediately. I find that participants who expect to complete Period 2 the following month are more optimistic about their Period 2 performance. The resulting optimism increases participants' willingness to borrow against their Period 2 performance (Experiment 1) and increases participants' willingness to accept a more challenging task environment in Period 2 (Experiment 2) in order to qualify for a Period 1 bonus. Mediation analyses indicate that this optimism fully accounts for the effect of the timing manipulation on participants' earnings management decisions. These results are consistent with horizon-induced optimism increasing both accruals management and real earnings management.

My experimental design allows me to rule out several alternative explanations for my results. For example, delaying Period 2 until the following month does not actually improve participants' performance in Period 2 and actually reduces participants' performance-based pay even though the incentive structures are identical. Further, the results are not driven by participants' beliefs that the intervening month will help them to realize better outcomes. My experiment also isolates the effect of the timing manipulation through beliefs about future performance by holding constant the timing of the payoffs for periods 1 and 2 across conditions, and my results cannot be explained by wishful betting or by rational or irrational discounting of payoffs that directly affect participants' preferences (e.g., Frederick, Loewenstein, and O’Donoghue 2002). 
My study also capitalizes on the comparative advantages of experiments (Libby, Bloomfield, and Nelson 2002). For example, my experimental approach allows me to capture more direct measures of optimism instead of inferring optimism from management forecasts, press statements, or operational decisions, allowing me to test how horizon-induced optimism affects earnings management decisions while controlling for innate optimism and strategic considerations that are normally confounded in these proxies for managers' private beliefs. My abstract experiments also allow me to create a control group to test my hypotheses while holding constant incentives, individual characteristics, and the information environment. Identifying an appropriate control group in archival datasets or with a less abstract experimental setting would be difficult because there is always a significant amount of time between the current period and the reversal period in practice. $^{2}$

My findings suggest that horizon-induced optimism could affect earnings management decisions in at least three ways. First, horizon-induced optimism might influence the overall level of earnings management observed in practice by systematically increasing managers' propensity to engage in earnings management that reverses in future periods. Second, the amount of time between the earnings management decision and the reversal will vary across earnings management techniques, and horizon-induced optimism should increase managers' willingness to engage in earnings management more as the amount of time increases. Finally,

\footnotetext{
${ }^{2}$ One possibility might be to exploit variation in the amount of time between the earnings management decision and future reversal across regulatory regimes (e.g., quarterly vs. semi-annual) or across earnings management techniques. However, exploiting this variation to test my hypotheses would be difficult because differences in regulatory regimes, managers' information set, and managers' strategic reporting incentives would be confounded with the length of the time delay. In addition, any control group would have a time delay of at least one reporting period, resulting in a weaker test of the effect of horizon-induced optimism on earnings management.
} 
horizon-induced optimism could lead managers to issue more optimistic long-horizon forecasts, thereby increasing market expectations and pressure to engage in earnings management in future periods.

These findings have potentially important implications for market participants and regulators. While managers who strategically engage in earnings management might benefit themselves or current shareholders (Bhojraj and Libby 2005), earnings management resulting from non-conscious processes such as horizon-induced optimism is more likely to have adverse consequences. For example, when firms fall short of market expectations in the current period, horizon-induced optimism could lead managers to engage in income-increasing earnings management because they overestimate their ability to compensate for current-period earnings management through strong future performance. Thus, horizon-induced optimism could start managers down a "slippery slope" where relatively benign earnings management escalates over time (e.g., Brown et al. 2011; Brown 2012; Schrand and Zechman 2012). ${ }^{3}$ Understanding how environmental factors might contribute to that optimism is an important first step to identifying effective interventions.

While experiments are not well-suited to estimating effect magnitudes in the real world, there are at least two reasons that the sign of my results is likely to generalize to the earnings management setting of interest. First, horizon-induced optimism is a fundamental psychological phenomenon, such that managers at various levels throughout organizations should be susceptible to these same errors. Second,

\footnotetext{
${ }^{3}$ The Phar-Mor fraud provides an anecdotal example of this type of pattern. Pat Finn, the former CFO, indicates that the fraud began with an initial misstatement and that "given time" they'd be able to "fix the problem." Even as the fraud ballooned, Finn states that he "always had a belief [they] could fix it" (see Frontline 1994).
} 
optimism is a primary facet of overconfidence (Skala 2008), and growing literatures in accounting and finance suggest that overconfidence affects a variety of managerial decisions (e.g., Hribar and Yang 2011; Malmendier and Tate 2005; Schrand and Zechman 2012), suggesting that optimism appears to be robust to the strong incentives and institutional forces present in these settings.

The remainder of this dissertation proceeds as follows. In Chapter 2, I provide background information and develop my hypotheses. I discuss the methods and results for Experiment 1 in Chapter 3 and the methods and results for Experiment 2 in Chapter 4. Chapter 5 provides additional discussion and analyses, and Chapter 6 provides concluding remarks. 


\section{CHAPTER 2}

\section{BACKGROUND AND DEVELOPMENT OF HYPOTHESES}

Managers regularly make operational and accounting decisions that affect reported performance in future periods, and there always is a timing difference between the current period and future periods in any periodic reporting setting. In this section, I develop hypotheses about how that timing difference affects beliefs about future performance and about potential implications for managers' disclosure and reporting decisions.

\subsection{The Optimism Bias}

People's expectations about the future are often unrealistically optimistic (see, e.g., Weinstein 1980). Evidence suggests that this "optimism bias" is a pervasive phenomenon, with approximately $80 \%$ of people expecting the future to be better than it ends up being (Sharot, Korn, and Dolan 2011; Sharot 2011; Strunk, Lopez, and DeRubeis 2006). Although the future may fall short of optimists' expectations, the optimism bias is probably functional most of the time (for a review, see Carver, Scheier, and Segerstrom 2010), as optimism is positively associated with health and longevity (Tindle et al. 2009), relationship quality (Assad, Donnellan, and Conger (2007), successful goal pursuit (Carver and Scheier 2001), and career achievement (Segerstrom 2007; Solberg Nes, Evans, and Segerstrom 2009).

Most theories of learning would suggest that the optimism bias shouldn't persist, as people should update their beliefs upon receiving new information (e.g., Pearce and Hall 1980; Sutton and Barto 1998). Yet, research finds that the optimism 
bias is common among people of all ages (Sharot 2011) and across levels of expertise (e.g., Baker and Emery 1993; Calderon 1993; Larwood and Whittaker 1977), suggesting the bias persists despite ample learning opportunities. Recent work in neuroscience indicates that the bias persists at least in part because human physiology favors optimism (e.g., Sharot, Riccardi, Raio, and Phelps 2007), perhaps due to its many apparent benefits. The evidence indicates that people asymmetrically update their beliefs more for favorable than unfavorable information about the future, and this asymmetric updating is correlated with independent measures of individuals' optimism. Further, disrupting the function of the brain region associated with coding favorable estimation errors attenuates the optimism bias whereas disrupting the function of the brain region associated with coding unfavorable estimation errors exacerbates the optimism bias. ${ }^{4}$

\subsection{The Effect of Time}

The above discussion highlights that people tend to be optimistic about the future. Several studies also indicate that people tend to be more optimistic about events that will occur in the more distant future than events that will occur in the near future. For example, the temporal distance to future events can change how individuals process information (e.g., Trope and Liberman 2003, 2010; White 2013), such that people considering the distant future underweight factors that might prevent positive outcomes (Nussbaum, Liberman, and Trope 2006), perceive future tasks as

\footnotetext{
${ }^{4}$ Specifically, Sharot et al. (2011) and Sharot et al. (2012) find that the inferior frontal gyrus (IFG) seems to track and integrate information into prior beliefs, with the left IFG tracking favorable estimation errors and the right IFG tracking unfavorable estimation errors. They find that lower activity in the right IFG predicts reduced belief-updating in response to unfavorable information about the future.
} 
being less difficult (Tsai and Thomas 2011), and focus on reasons they will succeed than reasons they might fail (Buehler, Griffin, and Ross 1994; Eyal, Liberman, Trope, and Walther 2004; Gilovich, Kerr, and Medvec 1993; Weinstein 1980). Affective processes also appear to contribute to this phenomenon, as emotions serve as one cue to optimism. Because people tend to experience less anxiety when future events are temporally distant, people feel more optimistic when considering the distant future (Sweeny, Carroll, and Shepperd 2006). Finally, motivational factors also appear to play a role, as individuals might feel less accountable and have greater latitude to adopt more favorable beliefs when self-relevant feedback is temporally distant (Kunda 1990; Lerner and Tetlock 1999; Shepperd et al. 1996). While cognitive, affective, and motivational factors all appear to contribute to this phenomenon, central to this study is that people are generally more optimistic when considering the distant future than when considering the near future. This leads to the following hypothesis:

H1: The amount of time between the current period and a future period increases managers' optimism about future performance.

\subsection{Earnings Management}

Prior work in accounting suggests that optimism increases managers' propensity to issue optimistic forecasts (Hribar and Yang 2011; Libby and Rennekamp 2012). One potential implication of $\mathrm{H} 1$ is that horizon-induced optimism could lead managers to set unrealistically optimistic market expectations that increase earnings management pressure in future periods (Kasznik 1999; Tan, Libby and Hunton 2002). However, horizon-induced optimism could also increase earnings management in the current period. Specifically, holding constant the magnitude of a current-period earnings 
shortfall, horizon-induced optimism should make managers more optimistic that they can meet future earnings targets even if they engage in incomeincreasing earnings management in the current period (Schrand and Zechman 2012).

One technique managers might use to increase current-period earnings is accruals management. Many types of income-increasing accruals management (e.g., overestimating percentage-of-completion, underestimating bad debts, etc.) involve borrowing earnings from future periods in order to increase income in the current period (Nelson, Elliott, and Tarpley 2003). Because these accruals reverse in subsequent periods, reported earnings in the future will be reduced by the same amount. If the amount of time between the current period and the reversal period increases managers' optimism about future performance, this horizon-induced optimism should increase managers' willingness to engage in accruals management because they believe they can borrow earnings from future periods and still successfully meet future earnings targets.

H2a: Horizon-induced optimism increases managers' propensity to engage in accruals-based earnings management.

An alternative technique managers might use to increase current-period earnings is real earnings management. Many types of real earnings management involve taking real economic actions (e.g., cutting discretionary spending or delaying the initiation of a new project) that increase earnings in the current period but also destroy firm value (Bhojraj and Libby 2005; Graham, Harvey and Rajgopal 2005; Roychowdhury 2006) so that meeting future earnings targets requires managers to post strong performance in a more challenging future operating environment. 
While horizon-induced optimism might increase managers' willingness to engage in real earnings management, finding support for $\mathrm{H} 2 \mathrm{a}$ does not necessarily imply that this relation will also hold for real earnings management. In contrast to accruals management, the effect of real earnings management on future earnings is somewhat uncertain, ${ }^{5}$ and this increased uncertainty could affect whether or how horizon-induced optimism affects real earnings management decisions. For example, the additional uncertainty could lead managers to reconsider and correct biased beliefs or prevent managers from acting on horizon-induced optimism in a real earnings management setting. Given these possibilities and the prevalence of real earnings management in practice (e.g., Cohen, Dey, and Lys 2008; Graham et al. 2005; Roychowdhury 2006), it is important to test whether horizon-induced optimism also affects real-earnings management.

H2b: Horizon-induced optimism increases managers' propensity to engage in real earnings management.

\footnotetext{
${ }^{5}$ For example, if managers intentionally overstate inventory by a certain amount, the reversal in the next period will be for the same amount. In contrast, there is more uncertainty about how cutting advertising might affect future earnings.
} 


\section{CHAPTER 3}

\section{EXPERIMENT 1}

\subsection{Method}

3.1.1 Design. Experiment 1 examines the effect of horizon-induced optimism on behavior that is analogous to accruals-based earnings management. As discussed previously, identifying an appropriate control group in archival data would be difficult because there is always a timing difference between the current period and future periods in a financial reporting environment. In addition, managers' information set and strategic reporting incentives would be confounded with the amount of time between the current period and a future period. I use an abstract task that allows me to test my hypotheses while capturing key aspects of the financial reporting environment. In the experiment, participants answer 25 trivia questions in each of two performance periods. ${ }^{6}$ As in a normal business setting, strong performance requires knowledge and effort, and higher performance on the task increases compensation. In addition, the task has clear performance metrics, involves multiple performance periods, and provides participants with performance feedback after Period 1 that they can use when considering whether to manage reported performance. I manipulate the amount of time between Period 1 and Period 2 in a 1 x 2 between-participant design. In the No Delay condition, participants expect to complete Period 2 “in just a few minutes." In the Delay condition, participants expect to complete Period 2 "next month." This design allows me to manipulate the amount of time to Period 2 while holding all other task information and incentives constant across conditions.

\footnotetext{
${ }^{6}$ My task is adapted from Libby and Rennekamp (2012). My Period 1 and Period 2 trivia questions correspond to their first- and second-round questions for participants in the "low-difficulty" condition. After compiling a bank of 180 trivia questions from the board game Trivial Pursuit (Hasbro 2008), Libby and Rennekamp (2012) used four independent raters to classify questions as "easy," "medium," or "hard." The raters were able to look at all trivia questions simultaneously. Questions were randomly selected from the set of questions where the majority of raters were able to agree on the level of difficulty.
} 


\subsubsection{Participants. Following Rennekamp (2012), I recruit 202 participants through}

Amazon's Mechanical Turk website. Amazon's Mechanical Turk (AMT) is an internet

crowdsourcing marketplace that allows "requesters" to pay "workers" to perform various tasks.

AMT is becoming an increasingly popular source for recruiting participants in academic research studies because the participant pool is large, readily accessible, and at least as representative of the U.S. population as traditional participant pools (for a review, see Mason and Suri 2012). In order to receive compensation for completing tasks, workers must have their work approved by requesters, which provides a review and rating system that incentivizes Workers to pay careful attention to the tasks. ${ }^{7}$ As will be explained in more detail below, my study is carried out over two sessions. Most participants complete the first session in about 8 minutes and the second session in about 6 minutes. ${ }^{8}$ Participants are paid $\$ 1$ for participating in each session of the study and receive an average performance bonus of $\$ 0.59$ if they participate in both sessions. $68.3 \%$ of participants participate in both sessions, for an effective hourly rate of about $\$ 11.10$. The remaining $31.7 \%$ of participants participate in only Session 1 for an effective hourly rate of about $\$ 7.50 .{ }^{9}$ These rates are well above the median wage for most tasks on AMT (Horton and Chilton 2010).

\footnotetext{
${ }^{7}$ To prevent Workers from having multiple accounts, AMT requires U.S. based workers to provide their social security number or individual tax identification number AMT. In addition, AMT prevents Workers from participating multiple times on the same task, and Qualtrics (which I use to distribute my survey) uses cookies to prevent participants from participating multiple times in the same study. Despite these precautions, 6 participants have the same IP address as participants from pilot testing. Because these participants may or may not be the same individuals who participated in my pilot study, I do not exclude them from analyses. They are randomly assigned across conditions, and inferences are unchanged when I exclude these participants.

${ }^{8}$ Start times and end times were tracked to the nearest minute. These times reflect the median difference between start and end times.

${ }^{9}$ As described in more detail below, I alleviate self-selection concerns in two ways. First, my primary analyses are based on the full sample of participants using only measures collected during the first experimental session. Second, the second experimental session takes place the following month for all participants, regardless of experimental condition. This design choice reduces the likelihood that my supplemental analyses are driven by self-selection, as any self-selection effect would have to vary across conditions to explain my results.
} 
Libby et al. (2002) suggest that participant selection should be driven by the demands and goals of the experiment. I restrict my sample to Workers within the United States who have an approval rate of at least $95 \%$, because my task requires participants to be able to read and understand English and pay careful attention to the task, but otherwise does not require any particular expertise. On average, participants are 31.7 years old and have 10.7 years of full-time work experience. $48.3 \%$ are female and $96 \%$ report being native English speakers. ${ }^{10}$ Given that the literature suggests that optimism is both pervasive and fundamental to human cognition, the sign of my results would be unlikely to differ if I had instead recruited experienced financial managers as participants.

\subsubsection{Procedures. Figure 2 provides a depiction of the experimental timeline. All} participants are informed that the study will involve two separate sessions, with the second session taking place the following month. Participants are informed that they will earn $\$ 1$ for each session and that by participating in both sessions, they will also be eligible for additional performance-based bonuses. ${ }^{11}$ After agreeing to participate in both sessions of the study, participants are provided additional information about the task. Specifically, they are told they will answer 25 trivia questions consisting of 15 easy, 5 medium and 5 hard questions, earn a $\$ 0.01$ performance bonus for each correct response, and have four minutes to answer these questions. All participants then complete Period 1 and receive feedback indicating the number of questions they answered correctly.

\footnotetext{
${ }^{10}$ Inferences are unchanged when I exclude participants who report they are not native English speakers.

${ }^{11}$ The performance bonus could not be calculated for participants in the Delay condition until after the second experimental session. Performance bonuses were paid only after all participants completed both parts of the study in order to avoid a between-condition timing difference of when participants received their performance bonus, which would introduce a discount-rate confound in the earnings management decision.
} 
Figure 2. Experimental Procedures

Session 1 - - - (One Month Delay) $-\longrightarrow$ Session 2
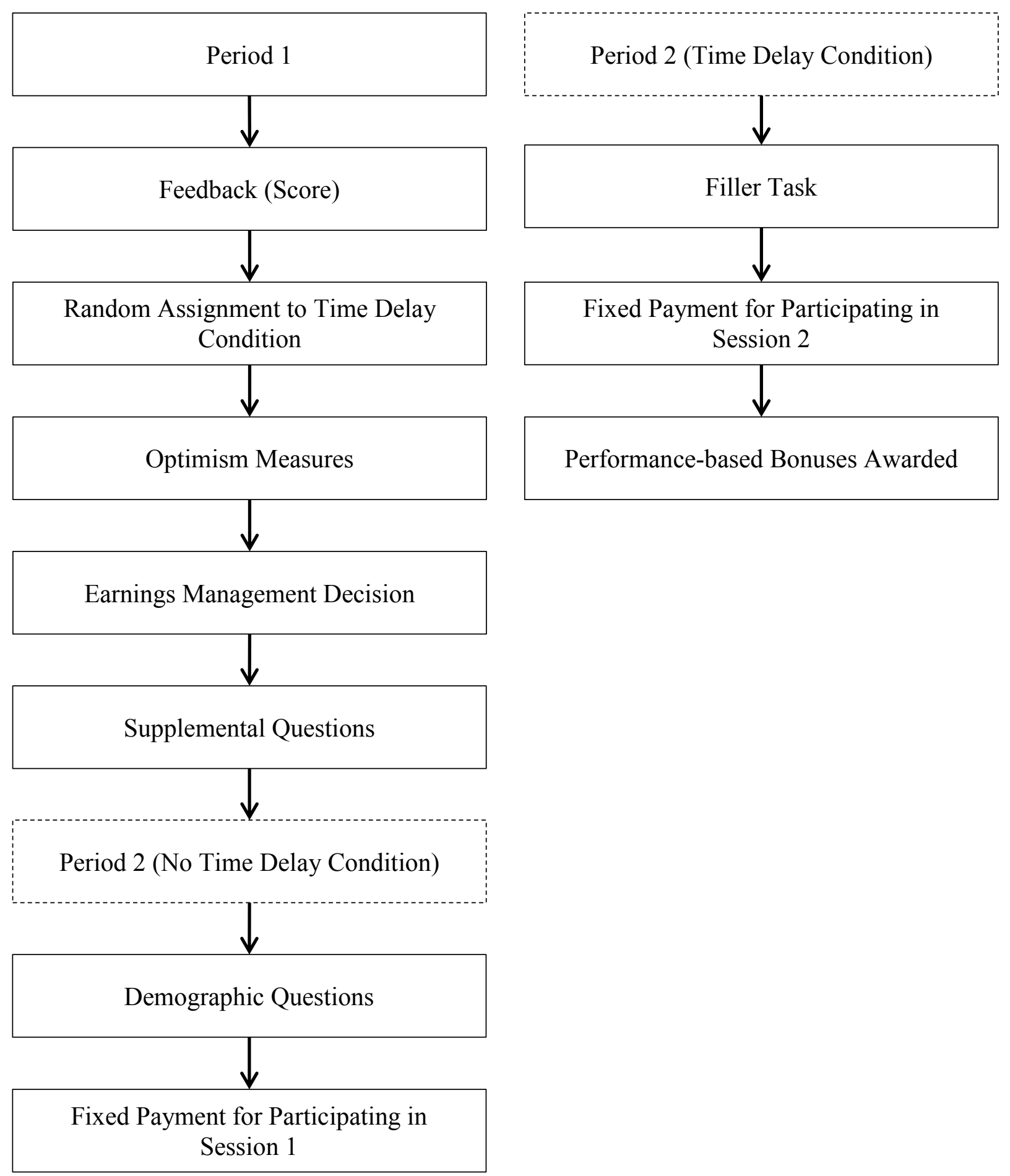
Participants are randomly assigned to one of two time delay conditions (TIME DELAY). Participants in the No Delay (Delay) condition are told they will answer an additional set of 25 trivia questions "in just a few minutes" ("next month") and that these questions will again consist of 15 easy, 5 medium and 5 hard questions. They are also informed they will earn a $\$ 0.01$ bonus for each correct response and will have only two minutes to answer these questions. Reducing the time limit from four to two minutes for Period 2 reduces the likelihood that participants' Period 2 forecasts are identical to their Period 1 performance while also ensuring that participants cannot simply use the internet to attain high performance in Period 2.

3.1.4 Dependent Measures. I collect two measures intended to capture participants' optimism. First, participants indicate how confident they are that they will perform at least as well on the second set of trivia questions as they did on the first set of trivia questions (CONFIDENCE, 11-point scale, where $1=$ "Not at all confident" and $11=$ "Very confident"). ${ }^{12}$ Next, participants provide an explicit forecast of the number of questions they expect to answer correctly on the second set of trivia questions (between 0 and 25). ${ }^{13}$ I use this forecast to construct a measure of

\footnotetext{
${ }^{12}$ Overconfidence can refer to overplacement of the mean (i.e., optimism) or to confidence intervals that are too narrow (i.e., "miscalibration;" see, e.g., Skala 2008). While my measure of confidence could refer to either facet of overconfidence, it appears to primarily capture optimism. Specifically, in pilot testing I elicited participants' estimates of the minimum and maximum number of questions they would correctly answer in Period 2. I found that confidence ratings were strongly positively associated with participants' estimates of both the minimum and maximum, but not with the width of the range. In addition, my time delay manipulation increased estimates of both the minimum and maximum, but did not affect the width of the range, providing evidence that the time delay affects optimism but not miscalibration. I omitted this measure of miscalibration from my two reported experiments because the construct it captured was clearly not distinct from participants' point estimates.

${ }^{13}$ Participants are instructed that their "estimate should be as accurate as possible" and that more accurate estimates will result in a larger performance bonus. Participants are awarded a bonus based on
} 
participants' forecast optimism (FORECAST OPTIMISM) by subtracting participants' Period 2 target from their forecast for Period 2. ${ }^{14}$

Participants also respond to a question designed to capture important features of income-increasing accruals management (see Panel A of the Appendix). Specifically, after forecasting their Period 2 scores, participants are told they can earn a $\$ 0.50$ performance bonus in Period 2 if they meet a performance target set equal to each participant's Period 1 score minus three. Pilot testing indicated that approximately half of the participants would meet or beat this target, which is set below their Period 1 score as a result of the reduced time limit in Period 2. Participants can choose whether to "borrow 4 correct responses" from their Period 2 performance to enhance their Period 1 score and earn a $\$ 0.50$ Period 1 bonus (EM DECISION). However, because the effect of borrowing reverses in Period 2, the Period 2 performance target increases by the borrowed amount, so participants who choose this option face a higher Period 2 target set equal to each participant's Period 1 score plus one. ${ }^{15}$ Participants are told they must meet or beat this higher Period 2 target in order to keep the Period 1 bonus and earn the Period 2 bonus. This design choice serves two functions. First, empirical evidence suggests that any stock price premium obtained through earnings management - one of the primary motivations for managing earnings (Graham et al. 2005) - dissipates immediately upon missing future benchmarks (Barth, Elliott, and Finn 1999; Myers et al. 2007). Consistent with this empirical the following formula: Bonus $=\$ 0.15-.01 * \mid$ Estimate - Actual|. |Estimate - Actual| is less than 15 for all participants.

${ }^{14}$ Using this ex ante measure of forecast optimism alleviates self-selection concerns. I examine ex post optimism (forecasted Period 2 performance - actual Period 2 Performance) in supplemental analyses. ${ }^{15}$ Thus, my design effectively holds constant the magnitude of the performance shortfall in Period 1 , as all participants can earn a Period 1 bonus by borrowing four correct responses from their Period 2 performance. 
evidence, participants in my study can realize benefits by managing earnings, but these benefits are maintained only if the performance target is met in Period 2.

Second, this design choice is critical from a methodological perspective. If participants were to keep the Period 1 bonus regardless of the level of Period 2 performance, managing earnings would be costless and all participants would choose to engage in accruals management.

\subsubsection{Additional Measures and Procedures. Following the earnings} management decision, participants indicate how they expect the reduced time limit to affect their performance in Period 2. Participants respond on an 11-point scale with endpoints, $-5=$ "I will perform much WORSE than I would with more time" to $5=$ "I will perform much BETTER than I would with more time." Participants then indicate whether they believe they would perform worse, the same, or better if they were to complete Period 2 in the alternative time delay condition. That is, participants in the No Delay (Delay) condition indicate whether they would perform worse, the same, or better if they were to instead complete Period 2 "next month" ("just a few minutes from now"). Participants in the No Delay condition then answer the second set of 25 trivia questions and provide a revised rating of how the reduced time limit affected their performance on the second set of questions. All participants conclude the first session of the study by answering demographic questions.

All participants receive an email the following month inviting them to participate in the second session of the study. ${ }^{16}$ By participating in the second session of the study, participants receive an additional $\$ 1$ and become eligible to receive their

\footnotetext{
${ }^{16}$ Holding constant the timing of the second experimental session across conditions allows me to test whether any self-selection effects vary across condition.
} 
performance-based bonuses. Participants in the No Delay condition complete a filler task consisting of a pilot test for an unrelated study. Participants in the Delay condition complete the second set of 25 trivia questions, provide a revised rating of how the reduced time limit affected their performance on the second set of questions, and complete the filler task. I then calculate and pay performance bonuses to all participants who participate in both parts of the study.

\subsection{Results}

Table 1 shows descriptive statistics and univariate analyses for participants' Period 1 scores, confidence in their Period 2 performance, forecasts of their Period 2 score, accruals management decisions, and actual Period 2 scores.

3.2.1 Tests of Hypotheses. My first hypothesis predicts that a time delay between Period 1 and Period 2 will increase participants' optimism. I test this hypothesis using CONFIDENCE and FORECAST OPTIMISM as proxies for optimism (see Panel A of Table 2). Consistent with H1, I find that participants in the Delay condition are more confident than are participants in the No Delay condition that they will perform at least as well in Period 2 as they did in Period $1\left(\mathrm{p}<0.001\right.$, one-sided). ${ }^{17}$ In addition, I find that participants in the Delay condition issue more optimistic forecasts for Period 2 than participants in the No Delay condition $(\mathrm{p}<0.001$, onesided). These results strongly suggest that the time delay increases participants' optimism.

\footnotetext{
${ }^{17}$ Reported results control for participants' Period 1 score. Inferences are unchanged if I do not control for participants' Period 1 score.
} 
TABLE 1

Experiment 1: Descriptive Statistics and Univariate Analyses - Mean, (Standard Deviation), and [Median]

\begin{tabular}{|c|c|c|c|c|c|c|c|c|}
\hline \multirow[b]{2}{*}{ Variable } & \multicolumn{4}{|c|}{ Full Sample } & \multicolumn{4}{|c|}{ Participants Who Completed Both Session 1 and 2} \\
\hline & Overall & No Delay & & Delay & Overall & No Delay & & Delay \\
\hline Period 1 Score (out of 25) & $\begin{array}{c}16.624 \\
(4.471) \\
{[18.0]}\end{array}$ & $\begin{array}{c}16.790 \\
(4.477) \\
{[18.0]}\end{array}$ & $=$ & $\begin{array}{c}16.461 \\
(4.480) \\
{[18.0]}\end{array}$ & $\begin{array}{c}17.116 \\
(3.967) \\
{[18.0]}\end{array}$ & $\begin{array}{c}17.197 \\
(4.020) \\
{[18.0]}\end{array}$ & $=$ & $\begin{array}{c}17.042 \\
(3.945) \\
{[18.0]}\end{array}$ \\
\hline $\begin{array}{l}\text { Confidence in Period } 2 \\
\text { Performance relative to } \\
\text { Period } 1^{\dagger}\end{array}$ & $\begin{array}{c}7.455 \\
(2.382) \\
{[8.0]}\end{array}$ & $\begin{array}{c}6.890 \\
(2.242) \\
{[7.0]}\end{array}$ & $<$ & $\begin{array}{c}8.010^{* * *} \\
(2.394) \\
{[8.5]}\end{array}$ & $\begin{array}{c}7.246 \\
(2.336) \\
{[7.5]}\end{array}$ & $\begin{array}{c}6.773 \\
(2.081) \\
{[7.0]}\end{array}$ & $<$ & $\begin{array}{c}7.681^{* *} \\
(2.483) \\
{[8.0]}\end{array}$ \\
\hline $\begin{array}{l}\text { Forecasted Period } 2 \text { Score } \\
\text { (out of } 25)^{\dagger}\end{array}$ & $\begin{array}{c}15.752 \\
(4.283) \\
{[16.0]}\end{array}$ & $\begin{array}{c}14.970 \\
(4.574) \\
{[15.0]}\end{array}$ & $<$ & $\begin{array}{c}16.520^{* * *} \\
(3.848) \\
{[17.0]}\end{array}$ & $\begin{array}{c}15.812 \\
(4.247) \\
{[16.5]}\end{array}$ & $\begin{array}{c}14.970 \\
(4.791) \\
{[15.0]}\end{array}$ & $<$ & $\begin{array}{c}16.583^{* * *} \\
(3.540) \\
{[17.0]}\end{array}$ \\
\hline $\begin{array}{l}\text { Proportion of Participants } \\
\text { Engaging in Accruals } \\
\text { Management }{ }^{\dagger}\end{array}$ & 0.426 & 0.380 & $<$ & $0.471^{*}$ & 0.413 & 0.333 & $<$ & $0.486^{* *}$ \\
\hline Period 2 Score (out of 25) & N/A & $\begin{array}{c}12.900 \\
(3.935) \\
{[13.0]}\end{array}$ & & $\mathrm{N} / \mathrm{A}$ & $\begin{array}{c}13.000 \\
(3.742) \\
{[13.0]}\end{array}$ & $\begin{array}{c}13.106 \\
(3.705) \\
{[13.0]}\end{array}$ & $=$ & $\begin{array}{l}12.903 \\
(3.798) \\
{[13.0]}\end{array}$ \\
\hline & $\mathrm{n}=202$ & $\mathrm{n}=100$ & & $\mathrm{n}=102$ & $\mathrm{n}=138$ & $\mathrm{n}=66$ & & $\mathrm{n}=72$ \\
\hline $\begin{array}{l}\text { This table provides descriptiv } \\
\text { [Medians] for the No Delay a } \\
\text { Significance levels are indicat } \\
{ }^{\dagger} \text { One-tailed test. }\end{array}$ & $\begin{array}{l}\text { or various } \\
\text { nditions. } \\
* * \text {, and } *_{1}\end{array}$ & $\begin{array}{l}\text { captured in } \\
\text { g significar }\end{array}$ & & $\begin{array}{l}\text { nent } 1, \mathrm{se} \\
0.01,0.0\end{array}$ & $\begin{array}{l}\text { nting variab } \\
\text { vels, respec }\end{array}$ & (Standard D & & \\
\hline
\end{tabular}


TABLE 2

Experiment 1: Tests of Horizon-Induced Optimism and Implications for Accruals Management

Panel A: Tests of $\mathrm{H1}$

Test of the effect of TIME DELAY on CONFIDENCE

\begin{tabular}{|c|c|c|c|c|c|}
\hline Term & Expectation & Estimate & $\begin{array}{l}\text { Std. } \\
\text { Error }\end{array}$ & t-ratio & p-value \\
\hline Intercept & & 8.157 & 0.652 & 12.51 & $<0.001$ \\
\hline TIME DELAY & + & 1.095 & 0.324 & 3.38 & $<0.001^{\dagger}$ \\
\hline PERIOD I SCORE & & -0.075 & 0.036 & -2.08 & 0.039 \\
\hline
\end{tabular}

Test of the effect of TIME DELAY on FORECAST OPTIMISM

\begin{tabular}{lccccc}
\hline \multirow{2}{*}{ Term } & Expectation & Estimate & $\begin{array}{c}\text { Std. } \\
\text { Error }\end{array}$ & t-ratio & p-value \\
\hline Intercept & & 9.010 & 0.989 & 9.11 & $<0.001$ \\
TIME DELAY & + & 1.173 & 0.491 & 3.51 & $<0.001$ \\
PERIOD 1 SCORE & & -0.466 & 0.0551 & -8.46 & $<0.001$ \\
\hline
\end{tabular}

Panel B: Tests of $\mathbf{H 2 a}$

Test of the effect of CONFIDENCE on EM DECISION

\begin{tabular}{lcccc}
\hline \multirow{2}{*}{ Expectation } & Estimate & $\begin{array}{c}\text { Std. } \\
\text { Error }\end{array}$ & $\begin{array}{c}\text { Chi } \\
\text { Square }\end{array}$ & p-value \\
\hline Intercept & -1.329 & 0.845 & 2.47 & 0.116 \\
TIME DELAY & 0.071 & 0.311 & 0.05 & 0.819 \\
CONFIDENCE & 0.279 & 0.073 & 14.58 & $<0.001^{\dagger}$ \\
PERIOD 1 SCORE & -0.068 & 0.035 & 3.65 & 0.056 \\
For log odds of Manage/Don't Manage & & & & \\
\hline
\end{tabular}

Test of the effect of FORECAST OPTIMISM on EM DECISION

\begin{tabular}{lccccc}
\hline & Expectation & Estimate & $\begin{array}{c}\text { Std. } \\
\text { Error }\end{array}$ & $\begin{array}{c}\text { Chi } \\
\text { Square }\end{array}$ & p-value \\
\hline Intercept & -0.983 & 0.765 & 1.65 & 0.199 \\
TIME DELAY & 0.039 & 0.312 & 0.02 & 0.901 \\
FORECAST OPTIMISM & + & 0.232 & 0.056 & 16.97 & $<0.001^{\dagger}$ \\
PERIOD 1 SCORE & & 0.008 & 0.041 & 0.04 & 0.848 \\
For log odds of Manage/Don't Manage & & & & \\
\hline
\end{tabular}


TABLE 2 (Continued)

Experiment 1: Tests of Horizon-induced Optimism and Implications for Accruals Management

Tests of Mediation

\begin{tabular}{lcc}
\hline Description & $\begin{array}{c}\text { Sobel } \\
\text { Statistic }\end{array}$ & p-value \\
\hline $\begin{array}{l}\text { Test of the effect of TIME DELAY on EM DECISION } \\
\text { through CONFIDENCE }\end{array}$ & 2.53 & $0.006^{\dagger}$ \\
$\begin{array}{l}\text { Test of the effect of TIME DELAY on EM DECISION } \\
\text { through FORECAST OPTIMISM }\end{array}$ & 2.67 & $0.004^{\dagger}$ \\
\hline
\end{tabular}

VARIABLE DEFINITIONS:

CONFIDENCE = participants' response to the following: "how confident are you that you will perform at least as well as you did on the first set of questions?" Response is measured on an 11-point scale, where 1 = "Not at all Confident" and $11=$ "Very Confident"

$E M D E C I S I O N=$ Participants are coded as having managed earnings if they elect to borrow correct responses from the second period in an attempt to achieve both a first- and secondperiod bonus.

FORECAST OPTIMISM = Forecast - Period 2 Benchmark. Period 2 Benchmark $=$ Period 1

Score - 3

TIME DELAY = 1 if a participant was in the Delay condition and 0 otherwise.

PERIOD 1 SCORE = Number of correct responses (out of 25) in the first set of 25 trivia questions.

This table summarizes tests of my hypotheses. The variable(s) of interest for hypotheses are indicated with directional predictions shown under the "Expectation" heading in each panel.

${ }^{\dagger}$ One-tailed test.

H2a predicts that this optimism will increase participants' propensity to borrow correct responses from their future performance in an attempt to earn both a Period 1 and Period 2 bonus, analogous to engaging in accruals management. To test the effect of horizon-induced optimism on participants' accruals management decisions, I test whether CONFIDENCE mediates the effect of TIME DELAY on EM DECISION (e.g., MacKinnon, Fairchild, and Fritz 2007). I control for participants' Period 1 score and include TIME DELAY and CONFIDENCE in a logistic regression with EM $D E C I S I O N$ as the outcome variable. I find that TIME DELAY is not significant $(\mathrm{p}=$ 0.819, two-sided) while CONFIDENCE is highly significant ( $\mathrm{p}<0.001$, one-sided). A 
Sobel test confirms that CONFIDENCE significantly mediates the effect of TIME DELAY on EM DECISION ( $\mathrm{p}=0.006$, one-sided), indicating that TIME DELAY affects participants' EM DECISION through CONFIDENCE (see Panel B of Table 2). Inferences are unchanged if I instead use FORECAST OPTIMISM as a proxy for participants' optimism. Specifically, when TIME DELAY and FORECAST OPTIMISM are included in a logistic regression with EM DECISION as the outcome variable, I find that TIME DELAY is not significant $(\mathrm{p}=0.901$, two-sided $)$ while FORECAST OPTIMISM is highly significant ( $\mathrm{p}<0.001$, one-sided). A Sobel test confirms that FORECAST OPTIMISM significantly mediates the effect of TIME DELAY on EM $\operatorname{DECISION~(~} \mathrm{p}=0.004$, one-sided $)$.

These findings support the theoretical predictions depicted in Figure 1, indicating that TIME DELAY affects EM DECISION through horizon-induced optimism. My findings suggest that participants exhibit greater optimism when they expect to perform Period 2 the following month rather than immediately, even though they have exactly the same incentives and information about the upcoming task. This horizon-induced optimism increases participants' propensity to borrow from future performance in an attempt to qualify for a Period 1 bonus, analogous to accruals management. In addition, the lack of significance of TIME DELAY on EM DECISION after controlling for my measures of optimism provides no indication of an incremental effect of TIME DELAY on EM DECISION by directly changing participants' preferences (e.g., due to rational or irrational discounting of future payoffs, wishful betting, etc.). 
3.2.2 Ex Post Optimism. My primary analyses avoid self-selection concerns by relying only on measures collected during Session 1 of my experiment. However, this requires the assumption that participants in the Delay condition do not actually perform better in Period 2 than do participants in the No Delay condition. This assumption appears reasonable given that I find no evidence that TIME DELAY affects Period 2 scores for participants who participate in both sessions of the study $(\mathrm{p}=$ 0.751 , two-sided). ${ }^{18}$ Further, participants in the Delay condition earn lower performance-based bonuses than participants in the No Delay condition $(\mathrm{p}=0.097$, one-sided). As an alternative test of my hypotheses, I restrict my sample to participants who participated in both Session 1 and Session 2 of my experiment and test whether participants in the Delay condition issue more optimistic forecasts relative to their actual Period 2 performance (EX POST OPTIMISM) than participants in the No Delay condition, where EX POST OPTIMISM is the difference between participants' forecasts and their Period 2 score. I find that participants in the Delay condition exhibit more EX POST OPTIMISM (mean $=3.68$ questions) than do participants in the No Delay condition (mean $=1.86$ questions, $\mathrm{p}=0.013$, one-sided). Further, EX POST OPTIMISM significantly predicts participants' EM DECISION $(\mathrm{p}<$ 0.001, one-sided) and significantly mediates the effect of TIME DELAY on participants' EM DECISION ( $\mathrm{p}=0.029$, one-sided $)$. These results provide additional support for my hypotheses, suggesting that horizon-induced optimism increases

\footnotetext{
${ }^{18}$ I also find no difference if I compare Period 2 scores for participants in the Delay condition who completed both sessions to Period 2 scores for all participants in the No Delay condition ( $p=0.996$, two-sided).
} 
participants' propensity to engage in behavior that is analogous to accruals-based earnings management. ${ }^{19}$

\subsubsection{Plans to Improve during the Intervening Month. One potential}

explanation for my findings is that participants in the Delay condition expect to prepare for the Period 2 trivia task in the intervening month. To test this possibility, I ask participants to indicate how their performance would be affected by the timing of Period $2.73 .8 \%$ of participants indicate they would perform the same regardless of whether they were to complete Period 2 "just a few minutes from now" or "next month," and this is significantly greater than chance ( $p<0.001$, one-sided). $15.3 \%$ of participants indicate they would perform better "just a few minutes from now," whereas only $10.9 \%$ of participants indicate that they would perform better "next month." Thus, nearly $90 \%$ of participants indicate that delaying Period 2 until the following month would not improve their expected performance, and inferences are unchanged if I base analyses on only these participants. These findings suggest that participants do not intentionally exhibit horizon-induced optimism because they expect to improve their performance by preparing or practicing for Period $2 .^{20}$

\footnotetext{
${ }^{19}$ I find no evidence of self-selection across Time Delay conditions. Participants in the No Delay and Delay conditions are equally likely to participate in the second session $(p=0.484$, two-sided). While participants are more likely to participate in Session 2 when they are more confident ( $p=0.086$, twosided) and have lower Period 1 scores ( $\mathrm{p}=0.063$, two-sided), neither selection effect interacts with TIME DELAY ( $\mathrm{p}=0.431$, two-sided and $\mathrm{p}=0.870$, two-sided, respectively).

${ }^{20}$ I also find no evidence that TIME DELAY affects participants' perceptions of the effect of the time constraint on their performance ( $\mathrm{p}=0.894$, two-sided).
} 


\section{CHAPTER 4}

\section{EXPERIMENT 2}

Experiment 1 examines how the amount of time between the current period and the reversal period affects managers' accruals management behavior. While accruals management and real earnings management both make it more difficult to meet future earnings targets, the magnitude of the effect of real earnings management on future performance is more uncertain. As discussed previously, finding support for $\mathrm{H} 2 \mathrm{a}$ does not necessarily imply that horizon-induced optimism will have the same effect on real earnings management, because this heightened uncertainty could affect whether or how horizon-induced optimism affects real earnings management. In Experiment 2, I examine whether horizon-induced optimism affects participants' propensity to engage in behavior that is analogous to real earnings management.

\subsection{Method}

4.1.1 Design. I use the same task and design as Experiment 1. I manipulate, in a $1 \times 2$ between-participant design, the time delay between Period 1 and Period 2. As in Experiment 1, participants in the No Delay condition expect to complete Period 2 "in just a few minutes" while participants in the Delay condition expect to complete Period 2 "next month."

4.1.2 Participants. 206 participants recruited through Amazon’s Mechanical Turk participate in Experiment 2. ${ }^{21}$ Most participants complete the first session in

\footnotetext{
${ }^{21}$ Despite precautions taken to prevent repeat-participants, 12 participants have the same IP address as participants from pilot testing or Experiment 1. Because these participants may or may not be the same
} 
about 8 minutes and the second session in about 7 minutes. ${ }^{22}$ Participants are paid $\$ 1$ for participating in each session of the study and receive an average performance bonus of $\$ 0.58$ if they participate in both sessions. $67.0 \%$ of participants participate in both sessions, for an effective hourly rate of about $\$ 10.32$. The remaining $33.0 \%$ of participants participate in only Session 1 for an effective hourly rate of about $\$ 7.50$. On average, participants are 32.5 years old and have 11.2 years of full-time work experience. $57.3 \%$ are female and $99.0 \%$ report being native English speakers. ${ }^{23}$

\subsubsection{Procedures. Experiment 2 examines the effect of horizon-induced} optimism on behavior that is analogous to real earnings management. All procedures are identical to Experiment 1, with the following two exceptions. First, instead of choosing whether to borrow correct responses from their Period 2 performance to earn a Period 1 bonus, participants in Experiment 2 can choose to earn a Period 1 bonus by agreeing to trade five easy questions for five medium questions in Period 2, so that Period 2 consists of 10 easy questions, 10 medium questions and 5 hard questions rather than 15 easy questions, 5 medium questions and 5 hard questions (see Panel B of the Appendix). This choice is intended to be analogous to real earnings management in that it benefits Period 1 performance by changing the performance generating process resulting in a more challenging environment in the future. Second, in addition to asking participants to make an earnings management decision, I also ask

individuals who participated in my pilot study, I do not exclude them from analyses. They are randomly assigned across conditions, and inferences are unchanged when I exclude these participants.

${ }^{22}$ Start times and end times were tracked to the nearest minute. These times reflect the median difference between start and end times.

${ }^{23}$ Inferences are unchanged when I exclude participants who report they are not native English speakers. 
participants to rate how strongly they prefer the earnings management decision they made to the alternative they rejected (PREFERENCE STRENGTH). ${ }^{24}$

\subsection{Results}

Table 3 shows descriptive statistics and univariate analyses for participants' Period 1 scores, confidence in their Period 2 performance, forecasts of their Period 2 scores, real earnings management decisions, preference strength for their earnings management decision, and actual Period 2 scores.

4.2.1 Tests of Hypotheses. As in Experiment 1, I find strong evidence supporting H1 (see Panel A of Table 4), as TIME DELAY increases participants' CONFIDENCE $(\mathrm{p}<0.001$, one-sided $)$ and FORECAST OPTIMISM ( $\mathrm{p}=0.005$, onesided), confirming that the time delay increases participants' optimism about future performance.

$\mathrm{H} 2 \mathrm{~b}$ predicts that this optimism will increase participants' propensity to accept a more difficult task environment in an attempt to earn both a Period 1 and Period 2 bonus. I test whether CONFIDENCE mediates the effect of TIME DELAY on EM DECISION, controlling for participants' Period 1 score (see Panel B of Table 4). ${ }^{25}$ When both TIME DELAY and CONFIDENCE are included in a logistic regression with EM DECISION as the outcome variable, TIME DELAY is not significant ( $\mathrm{p}=0.651$, two-sided) while CONFIDENCE is highly significant ( $\mathrm{p}=0.002$, one-sided), and a Sobel test confirms a significant reduction in the effect of TIME DELAY ( $<<0.008$, one-sided). If PREFERENCE STRENGTH is used as the outcome variable,

\footnotetext{
${ }^{24}$ PREFERENCE STRENGTH is intended to provide an alternative and more sensitive measure of participants' preferences than the dichotomous choice.

${ }^{25}$ Inferences are unchanged if I do not control for participants' Period 1 score.
} 
a Sobel test again indicates the mediation is significant ( $\mathrm{p}=0.008$, one-sided). Inferences are similar if I instead use FORECAST OPTIMISM as a measure of participants' optimism. When both TIME DELAY and FORECAST OPTIMISM are included in a logistic regression with EM DECISION as the outcome variable, TIME DELAY is not significant ( $\mathrm{p}=0.445$, two-sided), FORECAST OPTIMISM is significant $(p=0.002$, one-sided), and a Sobel test confirms that the mediation is significant ( $\mathrm{p}=0.025$, one-sided). Mediation remains significant if PREFERENCE STRENGTH is used as the outcome variable (Sobel $\mathrm{p}=0.026$, one-sided).

These findings provide additional support for the theoretical predictions outlined in Figure 1, as participants are more optimistic about future performance when there is a significant time delay between periods. I also find that the resulting optimism mediates the effect of the time delay manipulation on participants' willingness to trade 5 easy questions for 5 medium questions, which is analogous to engaging in real earnings management that increases the difficulty of the environment and decreases expected earnings in future periods. In addition, the lack of significance of TIME DELAY on EM DECISION after controlling for my measures of optimism provides no indication of an incremental effect of TIME DELAY on EM DECISION by directly changing participants' preferences (e.g., rational or irrational discounting of future payoffs, wishful betting, etc.). 
TABLE 3

Experiment 2: Descriptive Statistics and Univariate Analyses - Mean, (Standard Deviation), and [Median]

\begin{tabular}{|c|c|c|c|c|c|c|c|c|}
\hline \multirow[b]{2}{*}{ Variable } & \multicolumn{4}{|c|}{ Full Sample } & \multicolumn{4}{|c|}{ Participants Who Completed Both Session 1 and 2} \\
\hline & Overall & No Delay & & Delay & Overall & No Delay & & Delay \\
\hline Period 1 Score (out of 25) & $\begin{array}{c}16.830 \\
(3.977) \\
{[18.0]}\end{array}$ & $\begin{array}{c}17.087 \\
(3.881) \\
{[18.0]}\end{array}$ & $=$ & $\begin{array}{c}16.573 \\
(4.074) \\
{[18.0]}\end{array}$ & $\begin{array}{c}17.326 \\
(3.149) \\
{[18.0]}\end{array}$ & $\begin{array}{c}17.800 \\
(2.807) \\
{[18.0]}\end{array}$ & $>$ & $\begin{array}{c}16.904^{*} \\
(3.388) \\
{[18.0]}\end{array}$ \\
\hline $\begin{array}{l}\text { Confidence in Period } 2 \\
\text { Performance relative to } \\
\text { Period } 1^{\dagger}\end{array}$ & $\begin{array}{c}7.413 \\
(2.393) \\
{[8.0]}\end{array}$ & $\begin{array}{c}6.738 \\
(2.240) \\
{[7.0]}\end{array}$ & $<$ & $\begin{array}{c}8.087^{* * *} \\
(2.360) \\
{[8.0]}\end{array}$ & $\begin{array}{c}7.348 \\
(2.472) \\
{[8.0]}\end{array}$ & $\begin{array}{c}6.492 \\
(2.258) \\
{[6.0]}\end{array}$ & $<$ & $\begin{array}{c}8.110^{* * *} \\
(2.418) \\
{[8.0]}\end{array}$ \\
\hline $\begin{array}{l}\text { Forecasted Period } 2 \text { Score } \\
(\text { out of } 25)^{\dagger}\end{array}$ & $\begin{array}{c}15.956 \\
(4.026) \\
{[17.0]}\end{array}$ & $\begin{array}{c}15.592 \\
(4.143) \\
{[16.0]}\end{array}$ & $<$ & $\begin{array}{c}16.320^{*} \\
(3.891) \\
{[17.0]}\end{array}$ & $\begin{array}{c}16.181 \\
(3.754) \\
{[17.0]}\end{array}$ & $\begin{array}{c}15.846 \\
(3.675) \\
{[15.0]}\end{array}$ & $=$ & $\begin{array}{c}16.479 \\
(3.823) \\
{[17.0]}\end{array}$ \\
\hline $\begin{array}{l}\text { Proportion of Participants } \\
\text { Engaging in Accruals } \\
\text { Management }^{\dagger}\end{array}$ & 0.592 & 0.553 & $=$ & 0.631 & 0.630 & 0.554 & $<$ & $0.699^{* *}$ \\
\hline Preference Strength ${ }^{\dagger}$ & $\begin{array}{c}6.029 \\
(2.719) \\
{[7.0]}\end{array}$ & $\begin{array}{c}5.767 \\
(2.808) \\
{[7.0]}\end{array}$ & $<$ & $\begin{array}{c}6.291^{*} \\
(2.614) \\
{[7.0]}\end{array}$ & $\begin{array}{c}6.254 \\
(2.680) \\
{[7.0]}\end{array}$ & $\begin{array}{c}5.723 \\
(2.815) \\
{[7.0]}\end{array}$ & $<$ & $\begin{array}{c}6.726^{* *} \\
(2.479) \\
{[8.0]}\end{array}$ \\
\hline Period 2 Score (out of 25$)^{\dagger}$ & $\mathrm{N} / \mathrm{A}$ & $\begin{array}{c}12.087 \\
(3.747) \\
{[13.0]}\end{array}$ & & $\mathrm{N} / \mathrm{A}$ & $\begin{array}{l}11.514 \\
(3.713) \\
{[12.0]}\end{array}$ & $\begin{array}{c}12.569 \\
(3.791) \\
{[13.0]}\end{array}$ & $<$ & $\begin{array}{c}10.575^{* * *} \\
(3.674) \\
{[11.0]}\end{array}$ \\
\hline $\begin{array}{l}\text { This table provides descriptive } \\
\text { [Medians] for the No Delay an } \\
\text { Significance levels are indicate } \\
{ }^{\dagger} \text { One-tailed test. }\end{array}$ & $\begin{array}{l}\mathrm{n}=206 \\
\text { or various } \\
\text { nditions. } \\
* * \text {, and * }\end{array}$ & $\begin{array}{l}\mathrm{n}=103 \\
\text { captured in } \\
\text { g significar }\end{array}$ & 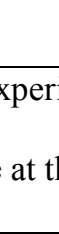 & $\begin{array}{l}\mathrm{n}=103 \\
\text { ent } 2 \text {, sep } \\
0.01,0.0\end{array}$ & $\begin{array}{r}\mathrm{n}=138 \\
\text { veling variabl } \\
\end{array}$ & $\frac{n=65}{\operatorname{tandard} D}$ & atiol & $\frac{\mathrm{n}=73}{\text { and }}$ \\
\hline
\end{tabular}


TABLE 4

Experiment 2: Tests of Horizon-Induced Optimism and Implications for Real Earnings Management

\section{Panel A: Test of $\mathrm{H1}$}

Test of the effect of TIME DELAY on CONFIDENCE

\begin{tabular}{lccccc}
\hline Term & Expectation & Estimate & $\begin{array}{c}\text { Std. } \\
\text { Error }\end{array}$ & t-ratio & p-value \\
\hline Intercept & & 6.435 & 0.730 & 8.82 & $<0.001$ \\
TIME DELAY & + & 1.359 & 0.322 & 4.22 & $<0.001^{\dagger}$ \\
PERIOD 1 SCORE & & 0.018 & 0.041 & 0.44 & 0.663 \\
\hline
\end{tabular}

Test of the effect of TIME DELAY on FORECAST OPTIMISM

\begin{tabular}{lccccc}
\hline \multirow{2}{*}{ Term } & Expectation & Estimate & $\begin{array}{c}\text { Std. } \\
\text { Error }\end{array}$ & t-ratio & p-value \\
\hline Intercept & & 6.842 & 0.934 & 7.33 & $<0.001$ \\
TIME DELAY & + & 1.082 & 0.412 & 2.63 & $0.005^{\dagger}$ \\
PERIOD 1 SCORE & & -0.312 & 0.052 & -6.01 & $<0.001$ \\
\hline
\end{tabular}

\section{Panel B: Tests of $\mathbf{H 2 b}$}

Test of the effect of CONFIDENCE on EM DECISION

\begin{tabular}{|c|c|c|c|c|c|}
\hline Term & Expectation & Estimate & $\begin{array}{l}\text { Std. } \\
\text { Error }\end{array}$ & $\begin{array}{l}\text { Chi } \\
\text { Square }\end{array}$ & p-value \\
\hline Intercept & & -2.667 & 0.825 & 10.46 & 0.001 \\
\hline TIME DELAY & & 0.139 & 0.308 & 0.20 & 0.651 \\
\hline CONFIDENCE & + & 0.19 & 0.066 & 8.38 & $0.002^{\dagger}$ \\
\hline PERIOD 1 SCORE & & 0.094 & 0.038 & 6.03 & 0.014 \\
\hline For log odds of Man & Manage & & & & \\
\hline
\end{tabular}

Test of the effect of FORECAST OPTIMISM on EM DECISION

\begin{tabular}{lccccc}
\hline \multirow{2}{*}{ Term } & \multirow{2}{*}{ Expectation } & \multirow{2}{*}{ Estimate } & $\begin{array}{c}\text { Std. } \\
\text { Error }\end{array}$ & $\begin{array}{c}\text { Chi } \\
\text { Square }\end{array}$ & p-value \\
\hline Intercept & & -2.512 & 0.797 & 9.93 & 0.002 \\
TIME DELAY & & 0.230 & 0.301 & 0.58 & 0.445 \\
FORECAST OPTIMISM & + & 0.155 & 0.053 & 8.59 & $0.002^{\dagger}$ \\
PERIOD 1 SCORE & & 0.146 & 0.043 & 11.71 & $<0.001$
\end{tabular}

For log odds of Manage/Don't Manage 
TABLE 4 (Continued)

Experiment 2: Tests of Horizon-induced Optimism and Implications for Real Earnings

Management

Tests of Mediation

\begin{tabular}{|c|c|c|}
\hline Description & $\begin{array}{c}\text { Sobel } \\
\text { Statistic }\end{array}$ & p-value \\
\hline $\begin{array}{l}\text { Test of the effect of TIME DELAY on EM DECISION } \\
\text { through CONFIDENCE }\end{array}$ & 2.39 & $0.008^{\dagger}$ \\
\hline $\begin{array}{l}\text { Test of the effect of TIME DELAY on EM DECISION } \\
\text { through FORECAST OPTIMISM }\end{array}$ & 1.96 & $0.025^{\dagger}$ \\
\hline
\end{tabular}

VARIABLE DEFINITIONS:

CONFIDENCE = participants' response to the following: "how confident are you that you will perform at least as well as you did on the first set of questions?" Response is measured on an 11-point scale, where 1 = "Not at all Confident" and $11=$ "Very Confident"

$E M D E C I S I O N=$ Participants are coded as having managed earnings if they elect to borrow correct responses from the second period in an attempt to achieve both a first- and secondperiod bonus.

FORECAST OPTIMISM $=$ Forecast - Period 2 Benchmark. Period 2 Benchmark $=$ Period 1 Score - 3

TIME DELAY = 1 if a participant was in the Delay condition and 0 otherwise.

PERIOD 1 SCORE $=$ Number of correct responses (out of 25) in the first set of 25 trivia questions.

This table summarizes tests of my hypotheses. The variable(s) of interest for hypotheses are indicated with directional predictions shown under the "Expectation" heading in each panel.

$\dagger$ One-tailed test.

4.2.2 Ex Post Optimism. Testing whether participants in the Delay condition issue more optimistic forecasts relative to their actual performance (EX POST OPTIMISM) is problematic in Experiment 2 because participants' EM DECISION affects EX POST OPTIMISM by changing the mix of question difficulty in Period $2 .{ }^{26}$ However, consistent with TIME DELAY leading participants to overestimate their performance in Period 2, participants in the Delay condition simultaneously issue

\footnotetext{
${ }^{26}$ Participants in the Delay condition exhibit more EX POST OPTIMISM than participants in the No Delay condition (p < 0.001, one-sided), but the effect of EM DECISION on EX POST OPTIMISM likely contributes to this effect. The result is robust to controlling for EMDECISION ( $\mathrm{p}=0.002$, one-sided $)$, but this p-value is potentially biased as a result of the simultaneity between EX POST OPTIMISM and EM DECISION. This simultaneity is also likely to bias the results of a formal mediation analysis.
} 
higher forecasts $(p=0.005$, one-sided $)$ and have lower Period 2 scores $(p=0.003$, one-sided) than participants in the No Delay condition. This latter effect appears to be driven by participants in the Delay condition who engage in real earnings management, as they perform significantly worse in Period 2 than participants in the No Delay condition who engage in earnings management $(p=0.014$, one-sided). For participants who do not engage in real earnings management, the effect of TIME $D E L A Y$ on Period 2 performance is not significant $(\mathrm{p}=0.458$, two-sided). Finally, I find that participants in the Delay condition earn lower performance-based bonuses than participants in the No Delay condition $(\mathrm{p}=0.088$, one-sided). These results suggest that the time delay increases participants' willingness to sacrifice future performance to qualify for a Period 1 bonus, which is analogous to real earnings management. $^{27}$

4.2.3 Plans to Improve during the Intervening Month. I again find no evidence to support the idea that the horizon-induced optimism results from participants in the Delay condition expecting to prepare for the Period 2 trivia questions in the intervening month. $71.8 \%$ of participants indicate that they would perform the same regardless of whether they were to complete Period 2 "just a few minutes from now" or "next month," and this is significantly greater than chance $(\mathrm{p}<0.001$, one-sided $)$. $18.0 \%$ of participants indicate they would perform better "just a few minutes from now," whereas only $10.2 \%$ of participants indicate they would perform better "next month." Thus, nearly $90 \%$ of participants indicate that delaying the Period 2 until the

\footnotetext{
${ }^{27}$ I again find no evidence that TIME DELAY affects participants' decision to participate in the second experimental session ( $\mathrm{p}=0.237$, two-sided). Participants are more likely to participate in the Session 2 when they have higher Period 1 scores $(p=0.008$, two-sided), but this selection effect does not differ across Time Delay conditions ( $\mathrm{p}=0.333$, two-sided $)$.
} 
following month would not improve their expected performance, and all inferences are unchanged if I base analyses on only these participants. These findings suggest that participants do not intentionally exhibit horizon-induced optimism because they expect to improve their performance by preparing or practicing for Period $2 .{ }^{28}$

\footnotetext{
${ }^{28}$ Participants in the Delay condition indicate that the reduced time limit will affect their performance less than participants in the No Delay condition ( $p<0.001$, one-sided), and this result holds for participants who engage in real earnings management $(\mathrm{p}=0.002$, one-sided $)$ and participants who do not engage in real earnings management $(\mathrm{p}=0.0529$, one-sided). Inferences are unchanged when I control for these ratings.
} 


\section{CHAPTER 5}

\section{ADDITIONAL DISCUSSION AND ANALYSIS}

\subsection{The Direct Effect}

The causal model depicted in Figure 1 suggests that TIME DELAY will affect EM DECISION through participants' optimism, so my primary analyses focus on this indirect effect. Early mediation analyses recommended a four-step approach, beginning with a test of the effect of the independent variable on the dependent variable (Baron and Kenny 1986). Contemporary methodologists generally advise against this approach, especially when there is no hypothesized direct effect or when using low-powered tests such as logistic regression that can prevent detection of interesting effects (e.g., MacKinnon 2007; MacKinnon et al. 2007). ${ }^{29}$ As indicated on Tables 1 and 3, the full sample provides mixed evidence of an effect of time delay on earnings management, with the effect of TIME DELAY on EM DECISION being marginally significant in Experiment $1(p=0.098$, one-sided $)$ and failing to meet conventional levels of significance in Experiment $2(p=0.161$, one-sided). Two findings suggest this is the result of a low-powered test (as opposed to the lack of an effect of TIME DELAY on EM DECISION).

First, in order to increase the power of the test, I combine my data from Experiment 1 and Experiment 2 and control for experiment. ${ }^{30}$ I find that TIME DELAY

\footnotetext{
${ }^{29}$ Indeed, on his website, David Kenny explicitly recommends against directly computing the direct effect when using logistic regression, suggesting that the total effect of the independent variable on the dependent variable should be inferred (http://davidakenny.net/cm/mediate.htm).

${ }^{30}$ Controlling for experiment jointly controls for any differences between the type of earnings management decision (accruals vs. real) and any potential differences in the participant pool
} 
significantly increases participants' propensity to engage in earnings management $(p=$ 0.044 , one-sided), and this effect does not vary by experiment ( $p=0.894$, two-sided). Second, an alternative way to increase power is to decrease noise. Some participants might not have actually planned on returning to complete Session 2 . These participants would be indifferent between managing and not managing earnings because they will not qualify for any performance-based bonuses, so their responses are likely to add noise. As indicated in Tables 1 and 3, after excluding participants who did not return for Session 2, the effect of TIME DELAY on EM DECISION is significant for Experiment $1(p=0.035$, one-sided $)$ and Experiment $2(p=0.022$, onesided). Together, these findings provide additional support for the causal model depicted in Figure 1.

\subsection{Compensation}

Earnings management is presumably costly, as managers might face several adverse consequences (e.g., job loss, reputational damage, etc.) if they are unable to compensate for current-period earnings management through strong future performance. Similarly, I design the incentive structure such that engaging in earnings management is costly if Period 2 performance is not sufficient to compensate for the earnings management. As indicated previously, participants in the Delay condition earn less than participants in the No Delay condition, though this result is only marginally significant, even though they face identical compensation structures. After combining data across experiments, this effect is significant $(p=0.035$, one-sided $) .{ }^{31}$

(participants were drawn from the same population within several days of each other, but participants were not randomly assigned across experiments).

${ }^{31}$ This effect does not vary across experiment $(\mathrm{p}=0.959$, two-sided $)$. 
In addition, I find that this effect is mediated by participants' EM DECISION ( $\mathrm{p}=$ 0.077, one-sided). These results are consistent with horizon-induced optimism leading participants in the Delay condition to engage in costly earnings management,

\subsection{Innate Optimism}

Recent work in behavioral finance and accounting examines how optimism affects managerial decisions, but most of this work focuses on optimism as a stable individual trait. In contrast, the differences I observe across conditions cannot be attributed solely to differences in participants' innate optimism. Unlike stable-trait optimism, horizon-induced optimism is unlikely to be attenuated by screening out optimistic individuals unless more optimistic individuals are more likely to exhibit horizon-induced optimism. To test this possibility, I invited participants in Experiments 1 and 2 to complete a follow-up survey. 117 participants completed Scheier, Carver, and Bridges' (1994) LOT-R, a measure of innate measure. ${ }^{32,33}$ I find no evidence that individuals with higher stable-trait optimism are more susceptible to horizon-induced optimism. Instead, the results are directionally consistent with the idea that the effect of TIME DELAY on CONFIDENCE and FORECAST OPTIMISM is decreasing in stable-trait optimism $(\mathrm{p}=0.254$, two-sided and $\mathrm{p}=0.113$, two-sided, respectively). These findings provide weak evidence that less optimistic individuals might be more likely to exhibit horizon-induced optimism than more optimistic individuals. However, these findings provide relatively strong evidence that screening

\footnotetext{
${ }^{32}$ I find no evidence that Time Delay affects participants' propensity to complete this follow-up survey ( $\mathrm{p}=0.573$, two-sided). In addition, while CONFIDENCE and FORECAST OPTIMSIM affect participants' propensity to complete this follow-up survey ( $\mathrm{p}=0.050$, two-sided and $\mathrm{p}=0.070$, twosided, respectively), these self-selection effects do not interact with Time Delay ( $\mathrm{p}=0.215$, two-sided and $\mathrm{p}=0.528$, two-sided, respectively).

${ }^{33}$ This measure asks participants to indicate their agreement with statements such as, "I' $m$ always optimistic about my future" (see also, Libby and Rennekamp 2011; Hales et al. 2012).
} 
managers based on measures of innate optimism is unlikely to be an effective intervention for horizon-induced optimism.

\subsection{Measures of Optimism}

My primary analyses rely on two measures of participants' optimism CONFIDENCE and FORECAST OPTIMISM. When both measures are included with TIME DELAY as predictors of EM DECISION, I find that CONFIDENCE and FORECAST OPTIMISM both remain significant for Experiment $1(\mathrm{p}=0.027$, onesided and $\mathrm{p}<0.001$, one-sided, respectively) and for Experiment $2(\mathrm{p}=0.073$, onesided and $p=0.052$, one-sided, respectively). While these two measures of optimism are correlated ( $\rho=0.559$ and $\rho=0.551$ in Experiments 1 and 2, respectively), it's possible these two measures are capturing slightly different facets of optimism (Cronbach's alpha $=0.651$ and 0.690 in Experiments 1 and 2, respectively). For example, CONFIDENCE might capture a general sense of participants' optimism while FORECAST OPTIMISM might capture a more deliberative and calculative measure of participants' optimism. Importantly, however, my time delay manipulation significantly affects both measures of optimism, suggesting that horizon-induced optimism is likely to affect behavior that is influenced by either or both facets of optimism. 


\section{CHAPTER 6}

\section{CONCLUSION}

I use two experiments to examine how the amount of time between the current period and the period when the earnings management reversal occurs affects optimism and earnings management, holding constant participants' incentives, participants' innate optimism, and the information environment. My results indicate that optimism about future performance is increasing in the length of this time delay, and this horizon-induced optimism increases participants' propensity to engage in behavior that is analogous to accruals-based and real earnings management.

My findings extend prior work by providing evidence that a fundamental feature of the earnings management setting can systematically induce optimism and increase earnings management, even holding constant factors to which earnings management has previously been attributed (e.g., agency frictions, capital market pressure, and innate optimism). My findings also indicate that optimism is most likely to be important in settings where there is a significant amount of time between the decision and the realization of its outcome. Consistent with this idea, prior work finds that management forecast optimism is increasing in the forecast horizon (Choi and Ziebart 2004; Hirst, Koonce, and Venkataraman 2008), although these authors attribute this result to management incentives to intentionally bias their forecasts. My results suggest that the amount of time between the forecast and the outcome might contribute to this pattern of forecast optimism, even absent these strategic reporting incentives. 
My findings might also have implications for the debate on reporting frequency, and future work might examine how the effect of horizon-induced optimism on earnings management depends on reporting frequency. Because the length of the time delay to the next period is decreasing in reporting frequency, one possibility is that horizon-induced optimism could work against myopic behavior as reporting frequency increases. However, another possibility is that horizon-induced optimism could exacerbate myopic behavior as reporting frequency increases, because the number of time delays between periods is increasing in reporting frequency.

The primary limitation of my study is my inability to assess the magnitude of the effect of horizon-induced optimism on either managers' beliefs or earnings management behavior in the real world. However, there is reason to expect that managers would be susceptible to these same errors given the neural mechanisms underlying optimism. In addition, optimism appears to affect various managerial decisions, suggesting that optimism is not fully disciplined by the strong incentives and institutional forces in these settings. The incentive structure in my experiment is designed to capture several important aspects of managers' incentives to manage earnings with the expectation of compensating for that behavior through strong future performance. The examination of other features of the reporting environment not captured in my study provides a potential avenue for future research. 


\section{APPENDIX}

\section{Panel A. Accruals Management Proxy (Experiment 1)}

You can earn a second round bonus of $\$ 0.50$ if you correctly answer at least [Period 1 Score -3 ] questions in the second round. However, if you're willing to borrow 4 correct responses from the second round to add to your first round score, you can earn a first round bonus of $\$ 0.50$ in addition to the second round bonus of $\$ 0.50$. If you choose this option, you would have to correctly answer at least [Period 1 Score +1 ] questions in the second round in order to keep this first round bonus and earn the second round bonus.

Please choose the bonus option you believe is most favorable to you:

- Option 1: If you answer at least [Period 1 Score - 3] questions correctly on the second round, receive a $\$ 0.50$ second round bonus.

- Option 2: If you answer at least [Period 1 Score + 1] questions correctly on the second round, receive a $\$ 0.50$ first round bonus and a $\$ 0.50$ second round bonus.

\section{Panel B. Real Earnings Management Proxy (Experiment 2)}

You can earn a second round bonus of $\$ 0.50$ if you correctly answer at least [Period 1 Score -3 ] questions in the second round. However, if you're willing to trade five easy questions for five medium questions on the second round, you can earn a first round bonus of $\$ 0.50$ in addition to the second round bonus of $\$ 0.50$. If you choose this option, you would have to correctly answer at least [Period 1 Score - 3] questions in the second round with 10 easy, 10 medium, and 5 hard questions in order to keep this first round bonus and earn the second round bonus.

Please choose the bonus option you believe is most favorable to you:

- Option 1: If you answer at least [Period 1 Score - 3] questions correctly on the second round with $\mathbf{1 5}$ easy, 5 medium, and 5 hard questions, receive a $\$ 0.50$ second round bonus.

- Option 2: If you answer at least [Period 1 Score - 3] questions correctly on the second round with 10 easy, 10 medium, and 5 hard questions, receive a $\$ 0.50$ first round bonus and a $\$ 0.50$ second round bonus. 


\section{REFERENCES}

Assad, K., M. B. Donnellan, and R. D. Conger. 2007. "Optimism: An enduring resource for romantic relationships." Journal of Personality and Social Psychology 93, no. 2: 285.

Baker, L. A., and R. E. Emery. 1993. "When every relationship is above average." Law and Human Behavior 17, no. 4: 439-450.

Baron, R. M., and D. A. Kenny. 1986. "The moderator-mediator variable distinction in social psychological research: Conceptual, strategic, and statistical considerations." Journal of personality and social psychology 51, no. 6: 11731182.

Barth, M. E., J. A. Elliott, and M. W. Finn. 1999. "Market rewards associated with patterns of increasing earnings." Journal of Accounting Research 37, no. 2: 387 413.

Bhojraj, S., P. Hribar, M. Picconi, and J. McInnis. 2009. "Making sense of cents: An examination of firms that marginally miss or beat analyst forecasts." The Journal of Finance 64, no. 5: 2361-2388.

Bhojraj, S., and R. Libby. 2005. "Capital market pressure, disclosure frequencyinduced earnings/cash flow conflict, and managerial myopia." The Accounting Review 80, no. 1: 1-20.

Brown, T. 2012. "Advantageous Comparison and the Slippery Slope to Earnings Management." Working paper, University of Illinois.

Brown, T., K. Rennekamp, N. Seybert, and W. Zhu. 2012. "Who Stands at the Top and Bottom of the Slippery Slope?" Working paper, University of Illinois and University of Maryland.

Buehler, R., D. Griffin, and M. Ross. 1994. "Exploring the" planning fallacy": Why people underestimate their task completion times." Journal of Personality and Social Psychology 67, no. 3: 366.

Calderon, T. G. 1993. "Predictive properties of analysts' forecasts of corporate earnings." MidAtlantic Journal of Business 29: 41-41.

Carver, C. S., and M. F. Scheier. 2001. On the Self-Regulation of Behavior. Cambridge University Press.

Carver, C. S., M. F. Scheier, and S. C. Segerstrom. 2010. "Optimism." Clinical Psychology Review 30, no. 7: 879-889. 
Choi, J. H., and D. A. Ziebart. 2004 "Management earnings forecasts and the market's reaction to predicted bias in the forecast." Asia-Pacific Journal of Accounting \& Economics 11, no. 2: 167-192.

Cohen, D. A., A. Dey, and T. Z. Lys. 2008. "Real and accrual-based earnings management in the pre-and post-Sarbanes-Oxley periods." The Accounting Review 83, no. 3: 757-787.

Eyal, T., N. Liberman, Y. Trope, and E. Walther. 2004. "The pros and cons of temporally near and distant action." Journal of Personality and Social Psychology: 781-795.

Frederick, S., G. Loewenstein, and T. O'donoghue. 2002 "Time discounting and time preference: A critical review." Journal of Economic Literature 40, no. 2: 351-401.

Gilovich, T., M. Kerr, and V. H. Medvec. 1993. "Effect of temporal perspective on subjective confidence." Journal of Personality and Social Psychology 64, no. 4: 552.

Graham, J. R., C. R. Harvey, and S. Rajgopal. 2005. "The economic implications of corporate financial reporting." Journal of Accounting and Economics 40, no. 1: 373.

Hales, J., L. Wang, and M. Williamson. 2012. "Selection Benefits of Stock-Based Compensation for the Rank-and-File." Working paper, Georgia Tech and University of Texas.

Hales, J., and S. J. Kachelmeier. 2008. "Predicting Relative Performance in Economic Competition." The Journal of Behavioral Finance 9, no. 4: 187-192.

Hasbro. 2008. Trivial Pursuit. [Board game]. Pawtucket, RI.

Hirst, D. E., L. Koonce, and S. Venkataraman. 2008. "Management earnings forecasts: A review and framework." Accounting Horizons 22, no. 3: 315-338.

Horton, J. J., and L.B. Chilton. 2010. "The labor economics of paid crowdsourcing." In Proceedings of the 11th ACM conference on Electronic commerce, pp. 209218. ACM.

Hribar, P., and H. Yang. 2012. "CEO overconfidence and management forecasting." Working paper, University of Iowa and University of Pennsylvania.

Hsee, C. K., and Y. Rottenstreich. 2004. "Music, pandas, and muggers: on the affective psychology of value." Journal of Experimental Psychology: General 133, no. 1: 23. 
Kadous, K., S. D. Krische, and L. M. Sedor. 2006. "Using counter-explanation to limit analysts' forecast optimism." The Accounting Review 81, no. 2: 377-397.

Kasznik, R. 1999. "On the Association between Voluntary Disclosure and Earnings Management." Journal of Accounting Research 37, no. 1: 57-81.

Kenny, D. A. "Mediation.” Last modified May 1, 2013, http://davidakenny.net/cm/mediate.htm.

Kunda, Z. 1990. "The case for motivated reasoning." Psychological Bulletin 108, no. 3: 480 .

Larwood, L., and W. Whittaker. 1977. "Managerial myopia: Self-serving biases in organizational planning." Journal of Applied Psychology 62, no. 2: 194.

Lerner, J. S., and P. E. Tetlock. 1999. "Accounting for the effects of accountability." Psychological bulletin 125, no. 2: 255.

Libby, R., R. Bloomfield, and M. W. Nelson. 2002. "Experimental research in financial accounting." Accounting, Organizations and Society 27, no. 8: 775-810.

Libby, R., and K. Rennekamp. 2012. "Self-Serving Attribution Bias, Overconfidence, and the Issuance of Management Forecasts." Journal of Accounting Research 50, no 1: 197-231.

MacKinnon, D. P., A. J. Fairchild, and M. S. Fritz. 2007. "Mediation Analysis." Annu. Rev. Psychol 58: 593-614.

Malmendier, U., and G. Tate. 2005. "CEO overconfidence and corporate investment." The Journal of Finance 60, no. 6: 2661-2700.

Mason, W., and S. Suri. 2012. "Conducting behavioral research on Amazon's Mechanical Turk." Behavior Research Methods 44, no. 1: 1-23.

Myers, J., L. Myers, and D. Skinner. 2007. "Earnings Momentum and Earnings Management." Journal of Accounting, Auditing and Finance 22, no. 2: 249-284.

Nelson, M. W., J. A. Elliott, and R. L. Tarpley. 2002. "Evidence from auditors about managers' and auditors' earnings management decisions." The Accounting Review 77, no. s-1: 175-202.

Nussbaum, S., N. Liberman, and Y. Trope. 2006. "Predicting the near and distant future." Journal of Experimental Psychology: General 135, no. 2: 152.

Pearce, J. M., and G. Hall. 1980. "A model for Pavlovian learning: variations in the effectiveness of conditioned but not of unconditioned stimuli." Psychological Review 87, no. 6: 532. 
Rennekamp, K. 2012. "Processing fluency and investors' reactions to disclosure readability." Journal of Accounting Research.

Roychowdhury, S. 2006. "Earnings management through real activities manipulation." Journal of Accounting and Economics 42, no. 3: 335-370.

Scheier, M. F., C. S. Carver, and M. W. Bridges. 1994. "Distinguishing optimism from neuroticism (and trait anxiety, self-mastery, and self-esteem): A reevaluation of the Life Orientation Test." Journal of personality and social psychology 67: 10631063.

Schrand, C. M., and S. L. C. Zechman. 2012. "Executive overconfidence and the slippery slope to financial misreporting." Journal of Accounting and Economics.

Segerstrom, S. C. 2007. "Optimism and resources: Effects on each other and on health over 10 years." Journal of Research in Personality 41, no. 4: 772-786.

Seybert, N., and R. Bloomfield. 2009. "Contagion of wishful thinking in markets." Management Science 55, no. 5: 738-751.

Sharot, T. 2011. "The optimism bias." Current Biology 21, no. 23: R941-R945.

Sharot, T., R. Kanai, D. Marston, C. W. Korn, G. Rees, and R. J. Dolan. 2012. "Selectively altering belief formation in the human brain." Proceedings of the National Academy of Sciences.

Sharot, T., C. W. Korn, and R. J. Dolan. 2011. "How unrealistic optimism is maintained in the face of reality." Nature Neuroscience 14, no. 11: 1475-1479.

Sharot, T., A. M. Riccardi, C. M. Raio, and E. A. Phelps. 2007. "Neural mechanisms mediating optimism bias." Nature 450, no. 7166: 102-105.

Shepperd, J. A., J. A. Ouellette, and J. K. Fernandez. 1996. "Abandoning unrealistic optimism: Performance estimates and the temporal proximity of self-relevant feedback." Journal of Personality and Social Psychology; Journal of Personality and Social Psychology 70, no. 4: 844.

Skala, D. 2008. "Overconfidence in psychology and finance-an interdisciplinary literature review." Bank i Kredyt 4: 33-50.

Solberg Nes, L., D. R. Evans, and S. C. Segerstrom. 2009. "Optimism and College Retention: Mediation by Motivation, Performance, and Adjustment1." Journal of Applied Social Psychology 39, no. 8: 1887-1912.

Strunk, D. R., H. Lopez, and R. J. DeRubeis. 2006. "Depressive symptoms are associated with unrealistic negative predictions of future life events." Behaviour Research and Therapy 44, no. 6: 861-882. 
Sutton, R. S., and A. G. Barto. 1998. Reinforcement learning: An introduction. Vol. 1, no. 1. Cambridge, MA: MIT press.

Sweeny, K., P. J. Carroll, and J. A. Shepperd. 2006. "Is optimism always best? Future outlooks and preparedness." Current Directions in Psychological Science 15, no. 6: 302-306.

Tan, H. T., R. Libby, and J. E. Hunton. 2002. "Analysts' reactions to earnings preannouncement strategies." Journal of Accounting Research 40, no. 1: 223-246.

Teoh, S. H., T. J. Wong, and G. R. Rao. 1998. "Are accruals during initial public offerings opportunistic?" Review of Accounting Studies 3, no. 1: 175-208.

Tindle, H. A., Y. F. Chang, L. H. Kuller, J. E. Manson, J. G. Robinson, M. C. Rosal, G. J. Siegle, and K. A. Matthews. 2009. "Optimism, cynical hostility, and incident coronary heart disease and mortality in the Women's Health Initiative." Circulation 120, no. 8: 656-662.

Trope, Y., and N. Liberman. 2003. "Temporal construal." Psychological review 110, no. 3: 403.

Trope, Y., and N. Liberman. 2010 "Construal-level theory of psychological distance." Psychological review 117, no. 2: 440.

Tsai, C. I., and M. Thomas. 2011. "When does feeling of fluency matter? How abstract and concrete thinking influence fluency effects." Psychological Science 22, no. 3: 348-354.

Weinstein, N. D. 1980. "Unrealistic optimism about future life events." Journal of Personality and Social Psychology 39, no. 5: 806.

White, B. J. 2013. "Do investors use fair value disclosures? The role of investment horizon. Working paper, University of Texas at Austin. 